Journal of Mathematics and Statistics 6 (2): 151-156, 2010

ISSN 1549-3644

(C) 2010 Science Publications

\title{
Generalized Finite Sequence of Fuzzy Topographic Topological Mapping
}

\author{
${ }^{1,2}$ Tahir Ahmad, ${ }^{2}$ Siti Suhana Jamian and ${ }^{2}$ Jamalludin Talib \\ ${ }^{1}$ Faculty of Science, ESciNano Research Alliance, \\ Ibnu Sina Institute for Fundamental Science Studies, \\ ${ }^{2}$ Department of Mathematics, \\ University Technology Malaysia, 81310 Skudai, Johor, Malaysia
}

\begin{abstract}
Problem statement: Fuzzy Topographic Topological Mapping (FTTM) was developed to solve the neuromagnetic inverse problem. FTTM consisted of four topological spaces and connected by three homeomorphisms. FTTM 1 and FTTM 2 were developed to present 3-D view of an unbounded single current source and bounded multicurrent sources, respectively. FTTM 1 and FTTM 2 were homeomorphic and this homeomorphism will generate another 14 FTTM. We conjectured if there exist $n$ elements of FTTM, then the numbers of new elements are $n^{4}-n$. Approach: In this study, the conjecture was proven by viewing FTTMs as sequence and using its geometrical features. Results: In the process, several definitions were developed, geometrical and algebraic properties of FTTM were discovered. Conclusion: The conjecture was proven and some features of the sequence appear in Pascal Triangle.
\end{abstract}

Key words: Fuzzy topographic topological mapping, sequence, Pascal triangle

\section{INTRODUCTION}

The human brain (Fig. 1a) is the most important structure in our body. It is also the most complex organized structure known to exist. There are four lobes in both halves of the cortex: Frontal, pariental, temporal and occipital. The outermost layer of the brain is called the cerebral cortex. The cerebral cortex has a total surface area of about $2500 \mathrm{~cm}^{2}$, folded in a complicated way, so that it fits into the cranial cavity formed by the skull of the brain. There are at least 1010 neurons in the cerebral cortex (Ahmad et al., 2008).

These neurons are the active units in a vast signalhandling network. When information is being processed, small currents flow in the neural system and produce a weak magnetic field (Fig. 1b), which can be measured non-invasively by a SQUID (Hamalainen et al., 1993) (Superconducting Quantum Interference Device) magnetometer.

Magnetic field readings obtained from SQUID give information for the process to determine location, direction and magnitude of a current source. This is called neuromagnetic inverse problem. Currently there is only a method for solving this problem, namely Bayesian that needs a priori information (data based model) and it is time consuming (Tarantola and Vallete, 1982). On the other hand, FTTM is a novel model for solving neuromagnetic inverse problem (Ahmad et al., 2008).

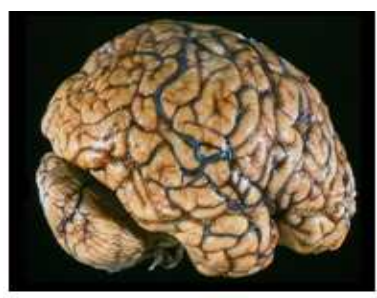

(a)

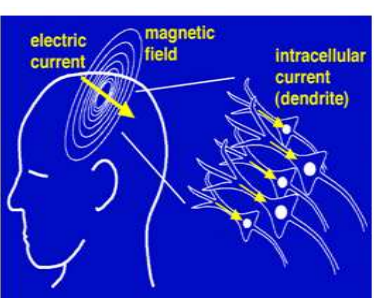

(b)
Fig. 1: (a): Human brain (b): Neuron magnetic field

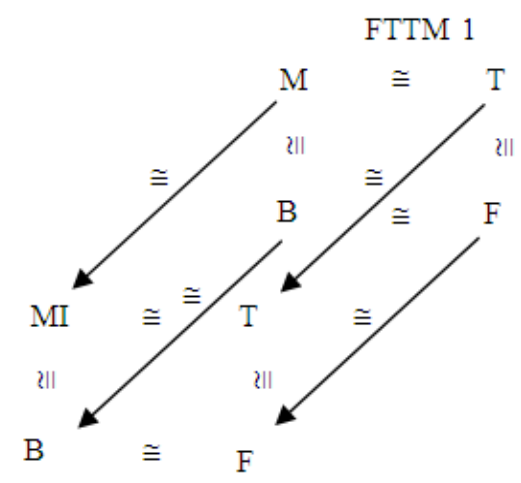

FTTM 2

Fig. 2: Homeomorphisms between FTTM 1 and FTTM 2

Corresponding Author: Tahir Ahmad, Faculty of Science, ESciNano Research Alliance,

Ibnu Sina Institute for Fundamental Science Studies, University Technology Malaysia, 81310 Skudai, Johor, Malaysia 
It does not need a priori information and it is less time consuming. The development of FTTM has been reported in sequentially. Its mathematical structures, algorithms and its initial performance is reported extensively in (Ahmad et al., 2005; 2008). FTTM 1 as well as FTTM 2 are specially designed to have equivalent topological structures between its components. In other words, each component of FTTM 1 and 2 is homeomorphic (Fig. 2) (Ahmad et al., 2005).

\section{MATERIALS AND METHODS}

Sequence of FTTM: Generally, FTTM can be represented as follows:

$\mathrm{FTTM}=\{(\mathrm{M}, \mathrm{B}, \mathrm{F}, \mathrm{T}): \mathrm{M} \cong \mathrm{B} \cong \mathrm{F} \cong \mathrm{T}\}$

$\left(\mathrm{M}^{\prime}, \mathrm{B}^{\prime}, \mathrm{F}^{\prime}, \mathrm{T}^{\prime}\right) \in \mathrm{FTTM}$ means that it satisfy the conditions of $\mathrm{M}, \mathrm{B}, \mathrm{F}$ and $\mathrm{T}$ respectively as given in (Ahmad et al., 2005) and $\mathrm{M}^{\prime} \cong \mathrm{B}^{\prime}, \mathrm{B}^{\prime} \cong \mathrm{F}^{\prime}$ and $\mathrm{F}^{\prime} \cong \mathrm{T}^{\prime}$.

We (Ahmad et al., 2005; 2008) proposed the following conjecture with regards in generating FTTM.

Conjecture: If there exist $\mathrm{n}$ elements of FTTM illustrated as then the numbers of new elements that can be generated are $n^{4}-n$ elements.

Even though it seems mathematical induction is most likely can be used to prove the conjecture, unfortunately it didn't work. This is due to the fact that Fig. 3 is a geometrical object while $n^{4}-n$ is an algebraic expression. Because of this reason, we need to deduce some geometrical features of FTTM in order to relate to the algebraic expression. The idea of deducing such features came from the study of $\mathrm{Wu}$ (1997) on Fibonacci Cubes.

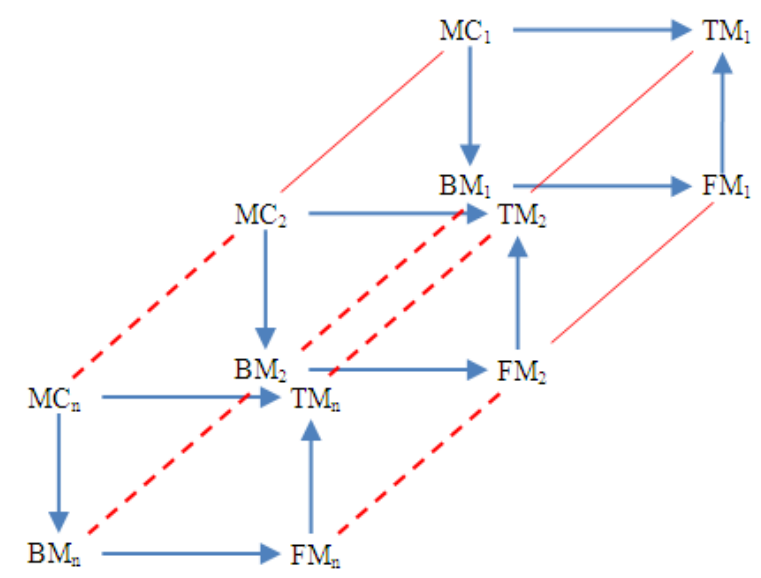

Fig. 3: FTTM $_{n}$
In order to extract some geometrical features of FTTM, we need to define on how our FTTMs will be arranged (Fig. 4).

Definition 1: Sequence of FTTM.

Let FTTM $_{\mathrm{i}}=\left(\mathrm{MC}_{\mathrm{i}}, \mathrm{BM}_{\mathrm{I}}, \mathrm{FM}_{\mathrm{i}}, \mathrm{TM}_{\mathrm{i}}\right)$ such that $\mathrm{MC}_{\mathrm{i}}$, $\mathrm{BM}_{\mathrm{I}}, \mathrm{FM}_{\mathrm{i}}, \mathrm{TM}_{\mathrm{i}}$ are topological space with $\mathrm{MC}_{\mathrm{i}} \cong \mathrm{BM}_{\mathrm{i}} \cong$ $\mathrm{FM}_{\mathrm{i}} \cong \mathrm{TM}_{\mathrm{i}}$. Set of FTTMi denoted by FTTM = $\left\{\right.$ FTTM $\left._{i}, \mathrm{i}=1,2,3, \ldots, \mathrm{n}\right\}$. Sequence of $\mathrm{n}$ FTTMi of FTTM is FTTM1, FTTM2, FTTM3,.., FTTMn such that $\mathrm{L} \mathrm{MC}_{\mathrm{i}} \cong \mathrm{MC}_{\mathrm{i}+1}, \mathrm{BM}_{\mathrm{i}} \cong \mathrm{BM}_{\mathrm{i}+1}, \mathrm{FM}_{\mathrm{i}} \cong \mathrm{FM}_{\mathrm{i}}, \mathrm{TM}_{\mathrm{i}} \cong$ $\mathrm{TM}_{\mathrm{i}}$.

As a start, let us look at FTTM $1, \mathrm{FTTM}_{2}, \mathrm{FTTM}_{3}$ and $\mathrm{FTTM}_{4}$ respectively in Fig. 5.

FTTM $_{1}$ can be viewed generally as a square and without loss of generality we can think MC, BM, FM and $\mathrm{TM}$ as vertices and the homeomorphism, i.e., $\mathrm{MC} \cong$ $\mathrm{BM}, \mathrm{BM} \cong \mathrm{FM}, \mathrm{FM} \cong \mathrm{TM}$ and $\mathrm{MC} \cong \mathrm{TM}$, as edges. FTTM 1 has 4 vertices and 4 edges.

Similarly FTTM ${ }_{2}$ contains 8 vertices, 12 edges, 6 faces and 1 cube. Generally a cube is a combination of 2 FTTM.

FTTM $_{3}$ consists of 12 vertices, 24 edges, 15 faces and 3 cubes.

FTTM $_{4}$ has 16 vertices, 28 edges, 16 faces and 6 cubes.

Consequently, we can observe some patterns of vertices, edges, faces and cubes emerging from sequences of FTTM as listed in the Table 1.

Definition 2: k-FTTM .

k-FTTM ${ }_{n}$ is the k-th FTTM of a sequence of $\mathrm{FTTM}_{\mathrm{n}}$ for $\mathrm{n} \geq \mathrm{k}$. For example, 1-FTTM $3,2-\mathrm{FTTM}_{3}$ and 3-FTTM 3 are given as follows (Fig. 6).

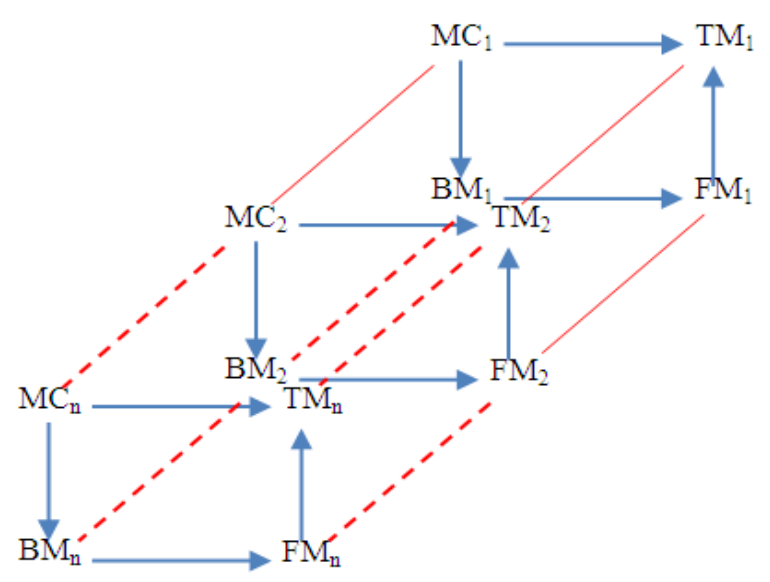

Fig. 4: Sequence of FTTM 


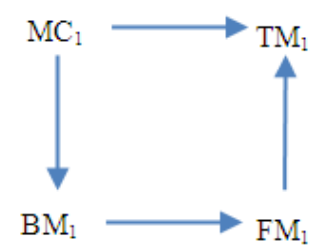

(a)

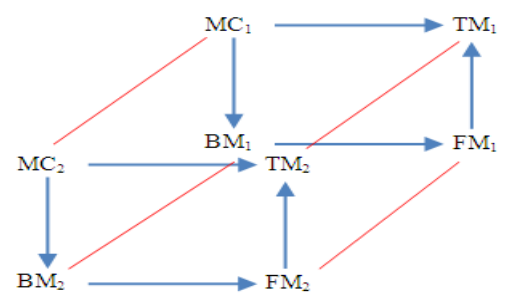

(b)

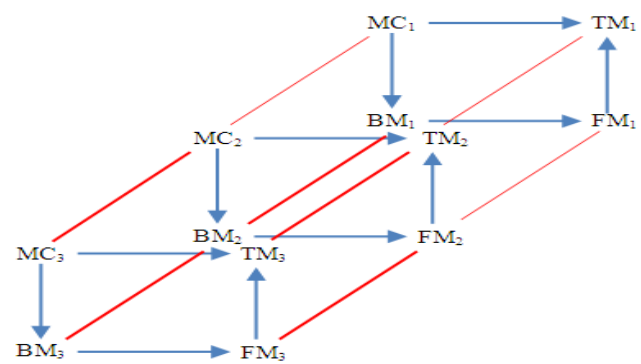

(c)

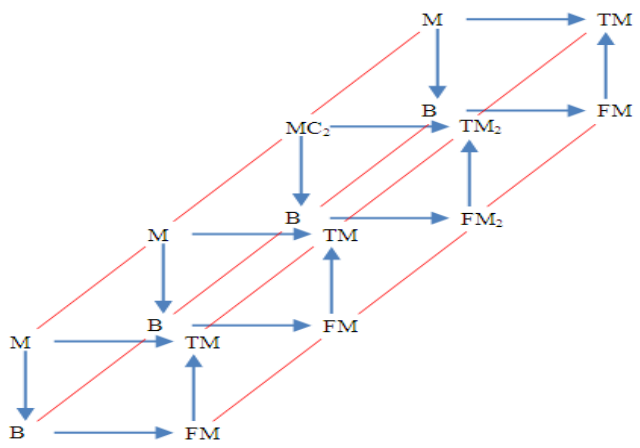

(d)

Fig. 5: (a): FTTM $_{1}$, (b): FTTM $_{2}$, (c): FTTM $_{3}$, (d): $\mathrm{FTTM}_{4}$

By defining sequence of FTTMs as given in the Definition 1, considering Table 1 and invoking to arithmetic sequence, we can have the following definition 3-6 which are analogous to the definition of Fibonacci sequence given in (Ahmad et al., 2005).

The sequence of vertices begins with the integers 4 , $8,12,16,20,24, \ldots$ and furthermore it is an arithmetic sequence with the difference between two consecutives terms is 4 . We can define formally the sequence of vertices as follows.
Definition 3: Sequence of Vertices of $\mathrm{FTTM}_{\mathrm{n}}$.

The sequence of vertices for $\mathrm{FTTM}_{\mathrm{n}}$. which is $v_{\text {vTTM }}, v_{\text {FTTM }}, v_{F T T M}, \ldots$ are given recursively by equation $\mathrm{vFTTM}_{n}=4 \mathrm{n}$ for $\mathrm{n} \geq 1$.

The sequence of edges begins with the integers 4 , $12,20,28,36, \ldots$ and furthermore it is an arithmetic sequence with the difference between two consecutives term is 8 . We can define formally the sequence of edges as follows.

Definition 4: Sequence of Edges of $\mathrm{FTTM}_{\mathrm{n}}$.

The sequence of edges for $\mathrm{FTTM}_{\mathrm{n}}$ which is eFTTM $_{1}$, eFTTM $_{2}$, eFTTM $_{3}, \ldots$ are given recursively by equation $\mathrm{eFTTM}_{\mathrm{n}}=4+(\mathrm{n}-1) 8$ for $\mathrm{n} \geq 1$.

The sequence of faces begins with the integers 1,6 , $11,16,21,26,31,36,41,46, \ldots$ and furthermore it is an arithmetic sequence with the difference between two consecutives term is 5 . We can define formally the sequence of faces as follows.

Definition 5: Sequence of Faces of FTTM $_{n}$.

The sequence of faces in $\mathrm{FTTM}_{\mathrm{n}}$ is $\mathrm{fFTTM}_{1}$, fFTTM $_{2}$, fFTTM $_{3}, \ldots$ are defined recursively by the equation fFTTM $_{n}=1+(n-1) 5$ for $\mathrm{n} \geq 1$.

The sequence of cubes begins with the integers 0 , $1,3,6,10,15,21, \ldots$ and so on. We can define formally the sequence of cubes as follows.

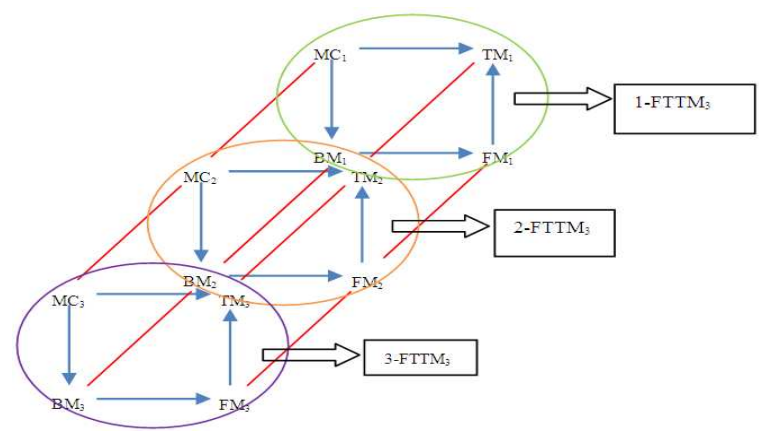

Fig. 6: 1-FTTM $3,2-\mathrm{FTTM}_{3}$ and 3-FTTM 3

Table 1: Vertices, edges, faces and cubes for sequence of FTTM

\begin{tabular}{lcccc}
\hline FTTM $_{n}$ & Vertices & Edges & Faces & Cubes \\
\hline 1 & 4 & 4 & 1 & 0 \\
2 & 8 & 12 & 6 & 1 \\
3 & 12 & 20 & 11 & 3 \\
4 & 16 & 28 & 16 & 6 \\
5 & 20 & 36 & 21 & 10 \\
6 & 24 & 44 & 26 & 15 \\
7 & 28 & 52 & 31 & 21 \\
8 & 32 & 60 & 36 & 28 \\
9 & 36 & 68 & 41 & 36 \\
10 & 40 & 76 & 46 & 45 \\
\hline
\end{tabular}


Table 2: Sequence of FTTM $_{2 / \mathrm{n}}$

\begin{tabular}{lcc}
\hline FTTM $_{\mathbf{n}}$ & FTTM $_{2 / \mathrm{n}}$ & $14 \mathrm{FTTM}_{2 / \mathrm{n}}$ \\
\hline FTTM $_{1}$ & 0 & 0 \\
FTTM $_{2}$ & 1 & 14 \\
FTTM $_{3}$ & 3 & 42 \\
FTTM $_{4}$ & 6 & 84 \\
FTTM $_{5}$ & 10 & 140 \\
FTTM $_{6}$ & 15 & 210 \\
FTTM $_{7}$ & 21 & 294 \\
FTTM $_{8}$ & 28 & 392 \\
FTTM $_{9}$ & 36 & 504 \\
FTTM $_{10}$ & 45 & 630 \\
\hline
\end{tabular}

Table 3: Sequence of $\mathrm{FTTM}_{3 / \mathrm{n}}$

\begin{tabular}{lcc}
\hline FTTM $_{n}$ & FTTM $_{3 / \mathbf{n}}$ & $36 \mathrm{FTTM}_{3 / \mathrm{n}}$ \\
\hline FTTM $_{1}$ & 0 & 0 \\
FTTM $_{2}$ & 0 & 0 \\
FTTM $_{3}$ & 1 & 36 \\
FTTM $_{4}$ & 4 & 144 \\
FTTM $_{5}$ & 10 & 360 \\
FTTM $_{6}$ & 20 & 720 \\
FTTM $_{7}$ & 35 & 1260 \\
FTTM $_{8}$ & 56 & 2016 \\
FTTM $_{9}$ & 84 & 3024 \\
FTTM $_{10}$ & 120 & 4320 \\
\hline
\end{tabular}

Definition 6: Sequence of Cubes of $\mathrm{FTTM}_{\mathrm{n}}$.

The sequence of cubes for FTTM $_{n}$ which is FTTM $_{2 / 1}$, FTTM $_{2 / 2}$, FTTM $_{2 / 3}, \ldots$ are given recursively by equation $\mathrm{FTTM}_{2 / \mathrm{n}}=\mathrm{FTTM}_{2 / \mathrm{n}}+(\mathrm{n}-1)$ for $\mathrm{n} \geq 1$.

By examining cube in FTTM, we can realize that cube exist from the combination of two terms of FTTM in FTTM $_{n}$ which in turn will generate another 14 new elements of FTTM. Therefore, Definition 6 can be rewritten as follows.

Definition 7: Sequence of $\mathrm{FTTM}_{2 / \mathrm{n}}$.

FTTM $_{2 / n}$ (Table 2) means the number of cubes produced by the combination of any two terms FTTM in FTTM with FTTM $2 / 1=0, \mathrm{FTTM}_{2 / 2}=1, \mathrm{FTTM}_{2 / 3}=3$, FTTM $_{2 / 4}=6$ and in general:

$\mathrm{FTTM}_{2 / \mathrm{n}}=\mathrm{FTTM}_{2 / \mathrm{n}-1}+(\mathrm{n}-1)$ for all $\mathrm{n}>1$

Cube in $\mathrm{FTTM}_{\mathrm{n}}$ can also be produced from the combination of three terms or three different versions of FTTM in FTTM $_{n}$. The combination will generate another 36 new elements of FTTM. Follows is the general definition and Table 3 demonstrates sequence of FTTM $_{3 / n}$ and its new elements.

Definition 8: Sequence of $\mathrm{FTTM}_{3 / \mathrm{n}}$.

$\mathrm{FTTM}_{3 / \mathrm{n}}$ means the number of cubes produced by the combination of any three terms FTTM in FTTM with FTTM $_{3 / 1}=0$, FTTM $_{3 / 2}=0$. Hence, FTTM FT/3 $_{3}=1$, FTTM $_{3 / 4}=4$, FTTM $_{3 / 5}=10$ and in general:

$\mathrm{FTTM}_{3 / \mathrm{n}}=\mathrm{FTTM}_{3 / \mathrm{n}-1}+\mathrm{FTTM}_{2 / \mathrm{n}-1}$ for all $\mathrm{n}>1$
Table 4: Sequence of FTTM $_{4 / \mathrm{n}}$

\begin{tabular}{lcc}
\hline FTTM $_{n}$ & FTTM $_{4 / \text { n }}$ & 24FTTM $_{4 / \mathrm{n}}$ \\
\hline FTTM $_{1}$ & 0 & 0 \\
FTTM $_{2}$ & 0 & 0 \\
FTTM $_{3}$ & 0 & 0 \\
FTTM $_{4}$ & 1 & 24 \\
FTTM $_{5}$ & 5 & 120 \\
FTTM $_{6}$ & 15 & 360 \\
FTTM $_{7}$ & 35 & 840 \\
FTTM $_{8}$ & 70 & 1680 \\
FTTM $_{9}$ & 126 & 3024 \\
FTTM $_{10}$ & 210 & 5040 \\
\hline
\end{tabular}

We have introduced that two and three terms FTTM in FTTM $_{n}$ can produce cubes. By extending the number of combination terms of FTTM to four, cube can also be produced and 24 new elements will be generated. Therefore, Definition 9 can be developed as following and Table 4 shows Sequence of FTTM $4 / \mathrm{n}$ and its new elements.

Definition 9: Sequence of $\mathrm{FTTM}_{4 / \mathrm{n}}$.

FTTM $_{4 / \mathrm{n}}$ means the number of cubes produced by the combination of any four terms FTTM in FTTM $_{n}$ with FTTM $_{4 / 1}=$ FTTM $_{4 / 2}=$ FTTM $_{4 / 3}=0$. Hence, FTTM $_{4 / 4}=1$, FTTM $_{4 / 5}=5$, FTTM $_{4 / 6}=15$ and in general:

$\mathrm{FTTM}_{4 / \mathrm{n}}=\mathrm{FTTM}_{4 / \mathrm{n}-1}+\mathrm{FTTM}_{3 / \mathrm{n}-1}$ for all $\mathrm{n}>1$

\section{RESULTS AND DISCUSSION}

It is impossible to continuing develop cube from the combination of five or more terms FTTM. Consequently, the number of generating FTTM in a sequence of FTTM $_{n}$ is the summation of the three versions of cubes; i.e., FTTM $2 / \mathrm{n}, \mathrm{FTTM}_{3 / \mathrm{n}}$ and FTTM $_{4 / \mathrm{n}}$. The coefficients for each version are 14, 36 and 24 respectively. The equation which represents the number of new elements of FTTM can be written as below:

$\mathrm{FTTM}_{\mathrm{n}}=14 \mathrm{FTTM}_{2 / \mathrm{n}}+36 \mathrm{FTTM}_{3 / \mathrm{n}}=24 \mathrm{FTTM}_{4 / \mathrm{n}}$ for $\mathrm{n}>1$

With:

$\mathrm{FTTM}_{2 / 1}+\mathrm{FTTM}_{3 / 1}=24 \mathrm{FTTM}_{4 / 1}=0$

Table 5 shows our generating FTTM $_{n}$. The highlighted columns clearly show that calculated generating FTTM using Eq. 1 is equal to Li Yun's conjecture for FTTM 1 until FTTM 10 .

Therefore, we need to write FTTM $_{2 / \mathrm{n}}, \mathrm{FTTM}_{3 / \mathrm{n}}$ and FTTM $_{4 / n}$ of Eq. 1 into algebraic expressions so that generating FTTM $_{n}$ can be used to prove the conjecture. 
Table 5: Comparison between generating FTTM to Li Yun's conjecture

\begin{tabular}{|c|c|c|c|c|c|}
\hline FTTM $_{n}$ & \multicolumn{2}{|c|}{$14 \mathrm{FTTM}_{2 / \mathrm{n}} 36 \mathrm{FTTM}_{3 / \mathrm{n}}$} & \multirow{2}{*}{$\begin{array}{l}2^{24 \mathrm{FTTM}_{4 / \mathrm{n}}} \\
24(0)\end{array}$} & \multirow[t]{2}{*}{$\begin{array}{c}\text { 14 } \mathrm{FTTM}_{2 / \mathrm{n}}+ \\
36 \mathrm{FTTM}_{3 / \mathrm{n}}+ \\
24 \mathrm{FTTM}_{4 / \mathrm{n}} \\
0\end{array}$} & \multirow{2}{*}{$\frac{n^{4}-n}{0}$} \\
\hline$\overline{\text { FTTM }}_{1}$ & $14(0)$ & $36(0)$ & & & \\
\hline $\mathrm{FTTM}_{2}$ & $14(1)$ & $36(0)$ & $24(0)$ & 14 & 14 \\
\hline $\mathrm{FTTM}_{3}$ & $14(3)$ & $36(1)$ & $24(0)$ & 78 & 78 \\
\hline FTTM $_{4}$ & $14(6)$ & $36(4)$ & $24(1)$ & 252 & 252 \\
\hline FTTM $_{5}$ & $14(10)$ & $36(10)$ & $24(5)$ & 620 & 620 \\
\hline FTTM $_{6}$ & $14(15)$ & $36(20)$ & $24(15)$ & 1290 & 1290 \\
\hline $\mathrm{FTTM}_{7}$ & $14(21)$ & $36(35)$ & $24(35)$ & 2394 & 2394 \\
\hline $\mathrm{FTTM}_{8}$ & $14(28)$ & $36(56)$ & $24(70)$ & 4088 & 4088 \\
\hline $\mathrm{FTTM}_{9}$ & $14(36)$ & $36(84)$ & $24(126)$ & 6552 & 6552 \\
\hline FTTM $_{10}$ & $14(45)$ & $36(120)$ & $24(210)$ & 9990 & 9990 \\
\hline
\end{tabular}

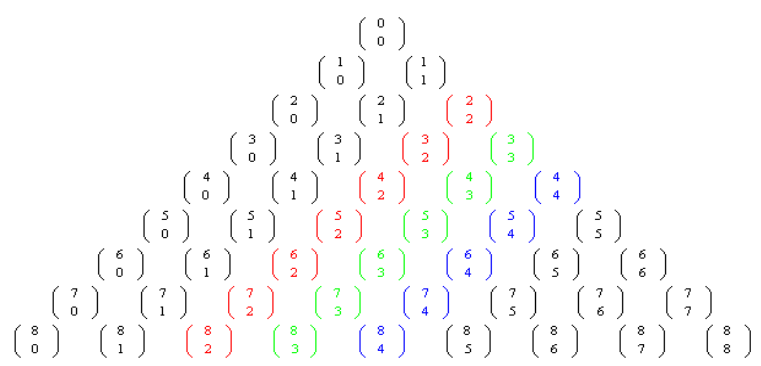

Fig. 7: Pascal triangle

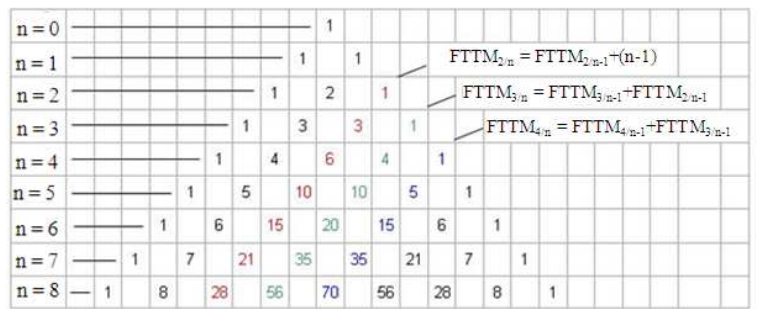

Fig. 8: Sequence of $\mathrm{FTTM}_{2 / \mathrm{n}}, \mathrm{FTTM}_{3 / \mathrm{n}}$ and $\mathrm{FTTM}_{4 / \mathrm{n}}$ in Pascal triangle

Interestingly, nonzero sequence of $\mathrm{FTTM}_{2 / \mathrm{n}}$, FTTM $_{3 / \mathrm{n}}$ and $\mathrm{FTTM}_{4 / \mathrm{n}}$ are presented in the third main diagonal (highlighted by red color), the fourth main diagonal (highlighted by green color) the fifth main diagonal (highlighted by blue color) of Pascal Triangle respectively as shown in Fig. 7.

Each binomial coefficient in Fig. 7 can be calculated and represented as another version of Pascal's Triangle as showed in Fig. 8.

The proof: As mentioned earlier, the problem in proving the conjecture is that the statement is not totally an algebraic statement. By revealing the geometrical features of FTTM and defining their characteristics we produced in Eq. 1. Moreover the third, fourth and fifth of the main diagonal of Pascal's Triangle represent the formulae of sequence of $\mathrm{FTTM}_{2 / \mathrm{n}}, \mathrm{FTTM}_{3 / \mathrm{n}}$ and FTTM $_{4 / \mathrm{n}}$ respectively as illustrated in Fig. 8. In short:

$$
\begin{aligned}
\operatorname{FTTM}_{2 / \mathrm{n}}=\left(\begin{array}{l}
\mathrm{n} \\
2
\end{array}\right) & =\frac{\mathrm{n} !}{(2) ![\mathrm{n}-(2)] !} \\
& =\frac{\mathrm{n}(\mathrm{n}-1)(\mathrm{n}-2) !}{2 !(\mathrm{n}-2) !} \\
& =\frac{\mathrm{n}(\mathrm{n}-1)}{2 !}
\end{aligned}
$$

$$
\begin{aligned}
\mathrm{FTTM}_{3 / \mathrm{n}}=\left(\begin{array}{l}
\mathrm{n} \\
3
\end{array}\right) & =\frac{\mathrm{n} !}{(3) ![\mathrm{n}-(3)] !} \\
& =\frac{\mathrm{n}(\mathrm{n}-1)(\mathrm{n}-2)(\mathrm{n}-3) !}{3 !(\mathrm{n}-3) !} \\
& =\frac{\mathrm{n}(\mathrm{n}-1)(\mathrm{n}-2)}{3 !}
\end{aligned}
$$

and

$$
\begin{aligned}
\mathrm{FTTM}_{4 / \mathrm{n}}=\left(\begin{array}{l}
\mathrm{n} \\
4
\end{array}\right) & =\frac{\mathrm{n} !}{(4) ![\mathrm{n}-(4)] !} \\
& =\frac{\mathrm{n}(\mathrm{n}-1)(\mathrm{n}-2)(\mathrm{n}-3)(\mathrm{n}-4) !}{4 !(\mathrm{n}-4) !} \\
& =\frac{\mathrm{n}(\mathrm{n}-1)(\mathrm{n}-2)(\mathrm{n}-3)}{4 !}
\end{aligned}
$$

By replacing Eq. 2-4 to Eq. 1, the conjecture is finally proven:

$$
\begin{aligned}
\text { FTTM }_{n}= & 14\left[\frac{\mathrm{n}(\mathrm{n}-1)}{2 !}\right]+36\left[\frac{\mathrm{n}(\mathrm{n}-1)(\mathrm{n}-2)}{3 !}\right] \\
& +24\left[\frac{\mathrm{n}(\mathrm{n}-1)(\mathrm{n}-2)(\mathrm{n}-3)}{4 !}\right] \\
= & 7 n(\mathrm{n}-1)+6 n(\mathrm{n}-1)(\mathrm{n}-2)+\mathrm{n}(\mathrm{n}-1) \\
& (\mathrm{n}-2)(\mathrm{n}-3) \\
= & n(n-1)[7+6(\mathrm{n}-2)+(\mathrm{n}-2)(\mathrm{n}-3)] \\
= & n(n-1)\left[7+6 n-12+n^{2}-3 n-2 n+6\right] \\
= & n^{2}-n\left[n^{2}+n+1\right] \\
= & n^{4}+n^{3}+n^{2}-n^{3}-n^{2}-n \\
= & n^{4}-n
\end{aligned}
$$

\section{CONCLUSION}

The aim of this study is to prove the conjecture proposed by (Yun, 2006). We highlighted that the left hand side of the conjecture is a 'geometrical object' in 
nature while the right hand side is an algebraic expression. Such characteristics of geometrical features that have been produced are sequence of vertices, sequence of edges, sequence of faces and sequence of cubes. These characteristics appeared in Pascal Triangle and were used to prove the conjecture.

\section{ACKNOWLEDGMENT}

The research is supported by Scientific Advancement Grant Allocation (SAGA) Fund. Ref. No: M 31 awarded by Ministry Of Science and Technology (MOSTI) and Academy of Science Malaysia (ASM).We would like also to thank Institute of Pediatrics Hospital Kuala Lumpur and Department of Neurosciences, School of Medical Sciences, HUSM for their assistance in this work as well as to the other members of Fuzzy Research Group (FRG), Department of Mathematics and Ibnu Sina Institute for Fundamental Science Studies, UTM for their cooperation.

\section{REFERENCES}

Ahmad, T., R.S. Ahmad, W.E.Z.W.A. Rahman, L.L. Yun and F. Zakaria, 2005. Homeomorphisms of Fuzzy Topographic Topological Mapping (FTTM). Matematika, 21: 35-42.

Ahmad, T., R.S. Ahmad, W.E.Z.W.A. Rahman, L.L. Yun and F. Zakaria, 2008. Fuzzy topographic topological mapping for localization simulated multiple current sources of MEG. J. Interdiscip. Math., 11: 381-393.
Hamalainen, M., J.I. Hari, J.K. Ilmoniemi and O.V. Lounasmaa, 1993. Magnetoencephalographytheory, instrument and application to non-invasive studies of the networking human brain. Rev. Modern Phys., 65: 413-497.

Tarantola, A. and B. Vallete, 1982. Inverse problems: Quest for information. J. Geophys., 50: 159-170.

Wu, J., 1997. Extended fibonacci cubes. IEEE. Trans. Parall. Distribut. Syst., 8: 1203-1210. DOI: 10.1109/71.640012

Yun, L.L., 2006. Group-like algebraic structures of fuzzy topographic topological mapping for solving neuromagnetic inverse problem. Ph.D. Thesis, University Technology Malaysia, Malaysia. 